\title{
Superior sagittal sinus thrombosis in a patient presenting with pregnancy induced hypertension and eclampsia
}

\author{
D Kumarasinghe ${ }^{1}$, A Ratnayake ${ }^{2}$, P Desilva $^{3 *}$, V Pinto $^{4}$ \\ Senior Registrar ${ }^{1 *}$, Registrar ${ }^{2}$, Department of Anaesthesia, Teaching Hospital, Kandy, Sri Lanka. \\ Honorary Senior Lecturer ${ }^{3}$, Professor of Anaesthesia and Critical Care ${ }^{4}$, Department of \\ Anaesthesia and Critical Care, University of Peradeniya, Sri Lanka.
}

*Corresponding author: ddesilva56@yahoo.com

A primi at 35 weeks of gestation presented with symptoms and signs of severe pregnancy induced hypertension. Soon after admission she developed eclampsia. A healthy baby was delivered by emergency lower segment cesarean section. The patient developed bilateral lower extremity weakness 12 hours after surgery. A contrast CT identified superior sagittal sinus thrombosis as the cause of her symptoms. The patient was anti-coagulated and made a complete recovery.

Keywords: Pregnancy induced hypertension; eclampsia; cerebral venous thrombosis; superior sagittal sinus thrombosis

\section{Case report}

A healthy 21 year old primi, presented with severe frontal headache and visual disturbances at 35 weeks of gestation. Blood pressure on admission was 160/100. She had hyper reflexia of all four extremities, with clonus at the ankles. Urine output was satisfactory, but urinalysis showed protein $3+$. She did not have epigastric discomfort or clinical evidence of pulmonary oedema. These symptoms and signs were new since her last antenatal clinic visit.

A diagnosis of pregnancy induced hypertension (PIH) and impending eclampsia was made. As soon as intravenous access was established, Magnesium Sulfate (MgSO4) 4g bolus was administered and an infusion started at a rate of $1 \mathrm{~g}$ per hour. Delivery by lower segment cesarean section (LSCS) was planned. Approximately 10 minutes after starting intravenous $\mathrm{MgSO} 4$ therapy, she developed generalized, tonic/clonic seizures. She had five generalized seizures within an hour of admission to the obstetric ward. As the seizures responded to $\mathrm{MgSO} 4$, no other anticonvulsants were administered. She was alert and oriented when she was brought to the operating room, approximately one hour and twenty minutes after admission. Rapid sequence induction of general anaesthesia

(GA) with thiopentone and suxamethonium was followed by tracheal intubation. GA was maintained with isoflurane in $100 \%$ oxygen till delivery. A healthy fetus, with 1 and 5 minute Apgar scores of 7 and 8, was delivered. At the conclusion of surgery, the trachea was extubated and she was transferred to the ICU. Her vital signs were stable and lab results showed; Haemoglobin $10.1 \mathrm{~g} / \mathrm{dl}$, platelet count of $213,000 / \mathrm{dl}$, random blood sugar $147 \mathrm{mg} / \mathrm{dl}$, serum creatinine $0.9 \mathrm{micromol} / \mathrm{dl}$, blood urea $23 \mathrm{mmol} / \mathrm{dl}$ and urine positive for protein $3+$. She was drowsy on arrival in the ICU, but showed no gross neurological deficits. Approximately 12 hours post-operatively, she developed bilateral lower extremity weakness. An emergency non-contrast CT showed bilateral para sagittal sub-cortical hypo density, suggestive of Superior Sagittal Sinus Thrombosis (SSST). A follow-up contrast enhanced CT showed a filling defect at the confluence of the Superior Sagittal and Transverse Sinuses, confirming a diagnosis SSST. There was also evidence of bilateral, para sagittal, cerebral infarction. An urgent haematology consultation was obtained. On the recommendations of the Consultant

(c) 2017. Kumarasinghe et al. This is an Open Access article distributed under the terms of the Creative Commons Attribution License (http: //creativecommons.org/licenses/by/4. 0), which permits unrestricted use, distribution, and reproduction in any medium, provided the original work is properly credited 
Haematologist, systemic anti-coagulation with i.v. heparin was commenced on post-operative day (POD) 1. Intravenous heparin therapy was guided by APPT. Once satisfactory anticoagulation was achieved, oral warfarin was started on POD 4. Her blood pressure responded to standard medication and urine was negative for protein on POD 2. The lower extremity paresis resolved completely on POD 7 and she was discharged on POD 12. A thrombotic screening was planned after three months as an outpatient, but she did not attend.

\section{Discussion}

The incidence of eclampsia is reported as $1 / 2000-3000$ deliveries in industrialized countries. ${ }^{1}$ With the onset of eclampsia, maternal mortality rate increases to $2 \%$ and fetal loss is reported as $7 \%$ in low-income countries. ${ }^{1,2}$ "De novo" grand mal seizures occurring in the setting of PIH, is the classical presentation and appeared to be the case in our patient. However, in $38 \%$ of patients, eclampsia may present without the features of PIH. ${ }^{1,3}$ The main differential diagnoses of eclampsia are; unrecognized head injury, meningitis, encephalitis, hypertensive encephalopathy, intra cranial haemorrhage (ICH) and cerebral venous thrombosis $(\mathrm{CVT}){ }^{3}$

She was lucid at presentation and gave no history of head injury. The patient was afebrile and had no evidence of CNS infection. Clinic data did not support a diagnosis of chronic hypertension. Findings were strongly suggestive of severe $\mathrm{PIH}$ and impending Eclampsia. However, hypertensive emergencies may also mimic severe PIH with proteinuria.

Had she responded to conservative therapy, induction with a trial of labour or LSCS, were the management options. However, with the onset of seizures, urgent LSCS was indicated and successfully performed, with a good maternal and fetal outcome.
In our patient, neither surgical nor anaesthetic factors could adequately account for her persistent post-operative drowsiness. Impaired mentation after ICH and CVT may closely mimic the post ictal state of eclampsia. CVT is a rare disease, with annual incidence of 3-4 per 1 million population. ${ }^{4}$ It is more frequent during pregnancy, with a reported incidence of 12 per 100,000 deliveries. ${ }^{4}$ The higher incidence may be due to the hyper-coagulable state associated with pregnancy. SSST is the commonest type of CVT. ${ }^{5,6}$ Our patient presented with features of severe PIH, progressed to eclampsia and then developed signs of SSST, 12 hours postoperatively. When she developed weakness of her legs, the need to exclude an intra-cranial pathology became paramount. Detection of SSST on CT/MRI is a dire finding, as cerebral infarction and maternal demise may result. ${ }^{7}$ Systemic anti-coagulation is the recommended treatment for $\mathrm{CVT}^{8}$ However, initiating systemic anti-coagulation immediately after surgery, with the attendant risk of visceral bleeding was a major clinical dilemma. A search of the PubMed database, failed to identify evidence-based guidelines for safely instituting full systemic anticoagulation on POD 1 after abdominal surgery. A metaanalysis concluded that, unfractionated heparin appeared to be safe for bridging anticoagulation, as bleeding complications were comparable to oral anticoagulation alone. ${ }^{9}$ This cohort consisted of 9534 patients who had mechanical cardiac valve implantation surgery. We relied on the expertise of a Consultant Haematologist who deemed that, despite the risk of bleeding, anti-coagulation was the best course of therapy to reverse SSST. To prevent the lower extremity weakness progressing to permanent paralysis. Our patient was extremely fortunate to have made a complete neurological recovery and not suffer any bleeding complications.

\section{Conclusion}

When a patient with eclampsia has a change in mental status or develops a new focal neurological deficit, other serious intracranial

(C) 2017. Kumarasinghe et al. This is an Open Access article distributed under the terms of the Creative Commons Attribution License (http: //creativecommons.org/licenses/by/4. 0), which permits unrestricted use, distribution, and reproduction in any medium, provided the original work is properly credited 
pathology must be excluded. We report an excellent maternal and fetal outcome, in a pregnancy complicated by PIH, eclampsia and SSST.

\section{References}

1. Goldenberg RL, Saleem S, Pasha O et al. Reducing stillbirths in low-income countries. Acta Obstetrics Gynecology Scand. 2016; 95(2): 135-43.

2. Cipolla M J, Kraig R P. Seizures in women with pre-eclampsia: Mechanisms and management. Fetal Maternal Med. Rev. 2011;22(02):91-108 https://doi.org/10.1017/S09655395110000 40 PMid:21709815 PMCid:PMC3119563

3. Beach R L, Kaplan P W. Seizures in pregnancy; diagnosis and management. International Review of Neurobiology. 2008;83:259-71.

https://doi.org/10.1016/S00747742(08)00015-9

4. Stam J. Thrombosis of cerebral veins and sinuses. New England Journal of Medicine,2005;352:1791-8. https://doi.org/10.1056/NEJMra042354 PMid:15858188
5. Bousser M, Chiras J, Bories J, Castaigne P. Cerebral venous thrombosis - A review of 38 cases. Stroke, 1985; 16(2): 199-213. https://doi.org/10.1161/01.STR.16.2.199 PMid:3975957

6. Sasidharan PK. Cerebral Vein Thrombosis misdiagnosed and mismanaged, Thrombosis, vol. 2012, Article ID 210676 , 11 pages. https://doi.org/10.1155/2012/210676

7. Soydinc H D, Ozler A, Evsen M S, et al. A case of cerebral sinus venous thrombosis resulting in mortality in severe preeclamptic pregnant woman. Case Reports in Obstetrics and Gynecology, vol. 2013, Article ID 402601, 3 pages. https://doi.org/10.1155/2013/402601

8. Khan M, Kamal A K, Wasay M. Controversies of treatment modalities for cerebral venous thrombosis. Stroke Research and Treatment, vol. 2010, Article ID956302,7pages. https://doi.org/10.4061/2010/956302

9. Passaglia LG, de Barros G M, de Sousa M R. Early postoperative bridging anticoagulation after mechanical heart valve replacement: a systematic review and meta-analysis. Journal of Thrombosis and Hemostasis, 2015;13(9):1557-67. https://doi.org/10.1111/jth.13047

(c) 2017. Kumarasinghe et al. This is an Open Access article distributed under the terms of the Creative Commons Attribution License (http: //creativecommons.org/licenses/by/4. 0), which permits unrestricted use, distribution, and reproduction in any medium, provided the original work is properly credited 